\title{
Co-seismic deformation derived from GPS observations during April 20th, 2013 Lushan Earthquake, Sichuan, China
}

\author{
Yujun Du $\cdot$ Zemin Wang $\cdot$ Shujiang Yang $\cdot$ \\ Jiachun An • Qiang Liu · Guowei Che
}

Received: 24 June 2013/Accepted: 4 September 2013/Published online: 30 October 2013

(C) The Seismological Society of China, Institute of Geophysics, China Earthquake Administration, and Springer-Verlag Berlin Heidelberg 2013

\begin{abstract}
We process the standard 30 s, static GPS data and the $1 \mathrm{~s}$, high-rate GPS (HRGPS) data provided by the Crustal Movement Observation Network of China with GAMIT/GLOBK software package, and obtain the coseismic displacements of near field and far field, and the epoch-by-epoch time series of HRGPS during Lushan earthquake. GPS data from about 20 sites in Sichuan province, which located between 40 and $450 \mathrm{~km}$ from the epicenter, are analyzed so as to study the characteristics of the static displacements and the dynamic crustal deformations, with periods ranging from several minutes to over a month. The result shows that: the static displacements caused by Lushan earthquake are limited to several centimeters; the nearest station SCTQ at $43 \mathrm{~km}$ from the epicenter has the largest static displacement of about $2 \mathrm{~cm}$, while the other stations generally have insignificant displacements of less than $5 \mathrm{~mm}$. the stations in the east of
\end{abstract}

Y. Du · Q. Liu

School of Geodesy and Geomatics, Wuhan University,

Wuhan 430079, China

Y. Du $\cdot$ Z. Wang $(\bowtie) \cdot$ J. An $\cdot$ G. Che

Chinese Antarctic Center of Surveying and Mapping, Wuhan University, Wuhan 430079, China

e-mail: zmwang@whu.edu.cn

\section{S. Yang}

Research Center of GNSS, Wuhan University, Wuhan 430079,

China

G. Che

Tianjin Institute of Surveying and Mapping, Tianjin 300381,

China
Sichuan-Yunnan region shifts $5-10 \mathrm{~mm}$ toward the southwest, and the stations in the middle-west of Sichuan Basin moves indistinctively 1-2 mm toward the northwest; station SCTQ has the largest kinematic displacement of about 4 and $3 \mathrm{~cm}$ peak-to-peak on the north and east component, respectively, and is much greater than the static permanent displacement; for the stations located at a distance greater than $150 \mathrm{~km}$ from the epicenter, the kinematic motions are generally insignificant; exceptionally, station SCNC and station SCSN in central Sichuan Basin have significant kinematic motions although they are more than $200 \mathrm{~km}$ away from the epicenter.

Keywords Lushan earthquake - GPS seismology · Co-seismic displacement . Time series

\section{Introduction}

On April 20th, 2013, an earthquake struck Lushan country of Ya'an city in Sichuan province, causing great damages. According to the China Earthquake Networks Center (CENC), the epicenter of this Ms7.0 earthquake, with a depth of $13 \mathrm{~km}$, is located at $30.3^{\circ} \mathrm{N}, 103.0^{\circ} \mathrm{E}$. After the strike, some institutes provided the focal solution and rupture process of Lushan earthquake by different means. The focal mechanism determined by Liu et al. (2013), Zeng et al. (2013), and Wang et al. (2013) separately indicates that the earthquake occurred at the south part of the Longmenshan fault zone is a thrust event; Zhang et al. (2013) conducted a fast inversion of the rupturing process of the earthquake by using the Global Seismic Network (GSN) teleseismic waveform data, showing that the main shock lasted for 10.5-27 s and most of the energy released in $10.5 \mathrm{~s}$; the focal solution provided by The 
Table 1 Epicentral distance of GPS stations

\begin{tabular}{|c|c|c|c|c|c|c|c|}
\hline Site & $\begin{array}{l}\text { Epicentral } \\
\text { distance/km }\end{array}$ & Site & $\begin{array}{l}\text { Epicentral } \\
\text { distance/km }\end{array}$ & Site & $\begin{array}{l}\text { Epicentral } \\
\text { distance/km }\end{array}$ & Site & $\begin{array}{l}\text { Epicentral } \\
\text { distance/km }\end{array}$ \\
\hline SCTQ & 42.7 & SCJL & 210.0 & SCLH & 272.7 & SCNN & 352.4 \\
\hline SCXJ & 116.8 & SCDF & 214.4 & SCNC & 272.8 & SCGY & 354.6 \\
\hline SCSM & 134.8 & SCXD & 223.6 & SCSP & 273.1 & SCXC & 355.5 \\
\hline SCMB & 155.6 & SCMN & 229.8 & SCML & 313.2 & SCBZ & 385.4 \\
\hline SCMX & 174.2 & SCSN & 231.4 & SCGZ & 339.1 & SCPZ & 434.1 \\
\hline SCYX & 184.5 & SCJU & 259.9 & SCYY & 348.1 & & \\
\hline
\end{tabular}

Global Centroid-Moment-Tensor (CMT) Project (Global CMT Web Page, http://www.globalcmt.org/) shows that the magnitude of the earthquake is Mw6.6 and the duration is about 10 s (Dziewonski et al. 1981; Ekström et al. 2012).

The focal mechanism, determined by observing the pattern of first motions of $\mathrm{P}$ waves, describes the patterns of fault movement and co-seismic deformation. However, this method can yet reproduce the real movement or deformation, and is limited in terms of the space-time characteristic of the earthquake, the distribution of the stations and the equipment (Yao and Zhang 2009; Wang et al. 2011).

Compared to focal mechanism solutions, GPS can be used to observe the deformations before and after the earthquake directly, compensating for those deficiencies described above. Years of conventional static GPS observations can be used to detect crustal movement, surface strain, and permanent displacement, providing information for analyzing the formation process, mechanisms and effects of an earthquake. High-rate GPS $(1-50 \mathrm{~Hz})$ can provide direct measurements of instantaneous deformation, which can be used to study the rupture process as well as postseismic motion (Meng et al. 2007). In this paper, we process the standard $30 \mathrm{~s}$, static GPS data, and the $1 \mathrm{~s}$, high-rate GPS data to obtain the co-seismic displacements of near field and far field and the epoch-by-epoch time series during Lushan earthquake, and then analyze the surface deformation during Lushan earthquake in different time scales.

\section{Data processing}

Twenty-three continuous stations installed by Crustal Movement Observation Network of China (CMONOC) in the area of Sichuan province with the data recorded at both $30 \mathrm{~s}$ sampling rate and $1 \mathrm{~s}$ sampling rate are used in our analysis. The data include 40 days' conventional static GPS data (30 s) from April 1st, 2013 (day 091) to May 10th, 2013 (day 130) and 3 days' HRGPS data (1 s) around April 20th (day 110). Some of the data are excluded because the qualities are bad (SCNN, 30 and $1 \mathrm{~s}$ ) or data sessions do not cover the earthquake (SCGZ, 30 and $1 \mathrm{~s}$; SCSP, SCML and SCBZ, $1 \mathrm{~s}$ ). Figure 2 shows the locations of these stations and the epicenter which is displayed as the red beachballliked focal mechanism diagram. The epicentral distances of the stations are showed in Table 1.

\subsection{Static processing}

We use the GAMIT/GLOBK software package (version 10.4) (Herring et al. 2010a, b) to conduct the static baseline processing and network adjustment. We use four IGS stations in the area of China including BJFS, LHAZ, URUM, and WUHN combined with the network of CMONOC in Sichuan to obtain the daily position solutions expressed with respect to the International Terrestrial Reference Frame 2008 (ITRF 2008). The time series derived from GAMIT/GLOBK are used to estimate the pre-seismic and post-seismic velocities and the co-seismic displacements. The data of day 110 are not used in the static analysis as the displacements of the stations caused by the main shock and the frequent aftershocks (Liu et al. 2013) make the single static solution not reliable.

According to the method described in the paper of Zhang (2008), we estimate the co-seismic displacement. Here we consider merely the linear trend of tectonic deformation. The long-term periodic deformation is treated to be linear in a short period of time, and the insignificant inter-seismic and post-seismic deformation is ignored. We use a shorter span (10 days) of the time series after the earthquake and give them less weight in order to reduce the impact of rapid post-seismic motion. Meanwhile, solutions closer in time to the earthquake occurrence are given larger weights. The co-seismic displacements are determined with a precision better than $1.5 \mathrm{~mm}$ on the horizontal components and $3.5 \mathrm{~mm}$ on the vertical components.

\subsection{Kinematic processing}

The HRGPS data is processed in relative positioning mode. We use TRACK (version 1.27), the kinematic module of 
the GAMIT/GLOBK software, to perform epoch-by-epoch solutions of the HRGPS data. TRACK uses floating point LC observations and the Melbourne-Wubbena wide-lane combination to determine the double-difference carrier phase integer ambiguities. We use the IGS final orbits, and adopt an elevation cut-off angle of $10^{\circ}$. We also use the global ionosphere maps (ftp://cddisa.gsfc.nasa.gov/pub/ gps/products/ionex/) to correct the higher order ionospheric effects, and global pressure and temperature model (GPT) (Boehm et al. 2007) model and global mapping function (GMF) (Boehm et al. 2006) to correct the tropospheric delay. The epoch-by-epoch solutions are estimated with the backward Kalman smoothing approach.

At least one reference station is required as TRACK performs relative kinematic positioning. A reference station should be with good data quality and stable position, be outside the epicentral area, but not be too far away from the kinematic stations (Xu et al. 2010; Xu et al. 2011; Yin et al. 2012). We use the TEQC software to evaluate the data quality (Estey and Meertens 1999). Based on the data analysis and the static positioning above, we choose SCXC and SCGY as the reference stations. We exclude the bad satellites (i.e., high multipaths) and keep the same selection of satellite during the full time window to improve stability of the solution.

We apply a modified sidereal filtering (Bock et al. 2000; Choi et al. 2004; Ragheb et al. 2007) to improve HRGPS positioning takes advantage of the ground track repeat period of the satellites. First, we process the data of day 109 and estimate the $1 \mathrm{~Hz}$ positions. The positions of day 109 are low-pass filtered to remove high-frequency noise, shifted by the mean satellite repeat period $(23 \mathrm{~h}, 55 \mathrm{~m}, 54 \mathrm{~s})$ and subtracted from the estimated positions on day 110. The method is described in detail in Ragheb et al. (2007). An example time series shown in Fig. 1 demonstrates its advantage.

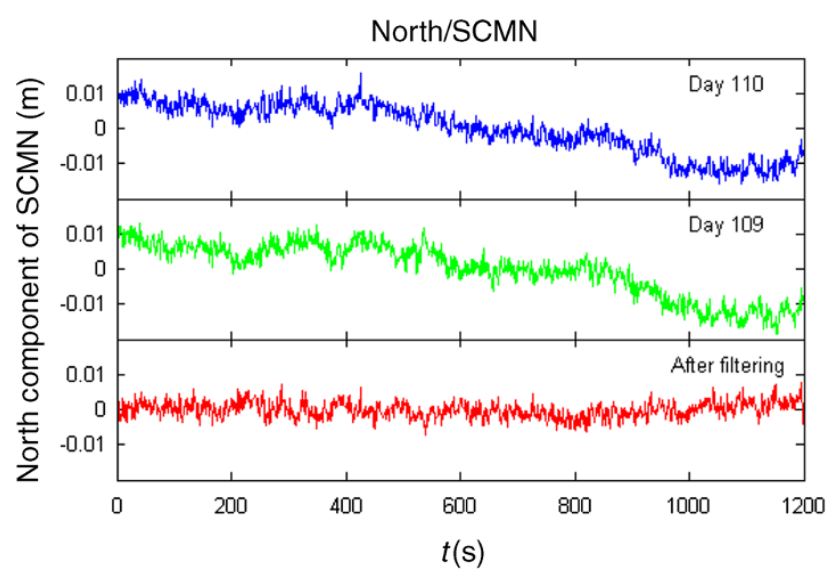

Fig. 1 Time series for north component of SCMN before and after sidereal filtering

\section{Co-seismic static displacements}

Horizontal co-seismic displacements of Lushan earthquake obtained from static GPS observations are shown in Fig. 2. As shown in the figure, the magnitude and direction of the co-seismic displacements, varying with different regions, indicate that the impacts of the earthquake on different regions are quite different. The station SCTQ, located at $1 \mathrm{~km}$ west of southern-range of Longmenshan front fault, is the nearest site from the epicenter $(43 \mathrm{~km})$ and suffers the largest displacement of about $2 \mathrm{~cm}$. SCXJ, located about $100 \mathrm{~km}$ away from the epicenter, has only about $3 \mathrm{~mm}$ displacement. As for further stations, the displacements are generally less than $5 \mathrm{~mm}$.

Western Sichuan is at the triple junction of the Bayan Har block, the Sichuan-Yunnan block, and the South China block (Sichuan Basin) (Zhang et al. 2003). Here it distributes many active fault zones, such as the Longmenshan fault zone, the Xianshuihe fault zone, the Anninghe-Zemuhe fault zone, and the Daliangshan fault zone. The coseismic static displacements of the sites in different block regions have different magnitudes and directions, while the sites in the same block region basically have the same displacements characteristics. Almost all stations in eastern Sichuan-Yunnan block region shift 2-5 mm toward southwest. Stations in the middle-west of Sichuan Basin move 1-2 $\mathrm{mm}$ toward the northwest generally.

SCTQ and SCXJ, the two closest stations from the epicenter, have large displacements with different directions. SCXJ, in cross-strike (ca. NW-SE) direction of the causative faults, shifts toward the fault zone. The along-strike (ca. NE-SW) located station SCTQ moves along the fault zone.

For the vertical displacements, as shown in Fig. 3, we can see that the magnitudes are relatively small. The largest displacement is only $12 \mathrm{~mm}$ (SCJL). The sites with larger vertical displacements are basically distributed in the east of Sichuan-Yunnan block region and the southwest of Sichuan Basin. By contrast, the sites inside Sichuan Basin and at the northeast of the Bayan Har block region suffer slighter vertical displacements. Almost all stations uplift, which may result from the blocks squeezing each other. However, the vertical displacements are not obvious compared to the large scatter in the vertical daily positions.

Permanent displacements can be seen intuitively from the $3 \mathrm{D}$ components time series of daily positions. Figure 4 shows the day-by-day 3D time series of SCTQ and SCXJ. There are slips occurred on day 110 at both of the stations, without recovery. As a result of the large scatter in vertical components, it is difficult to distinguish the vertical displacements from the time series. 


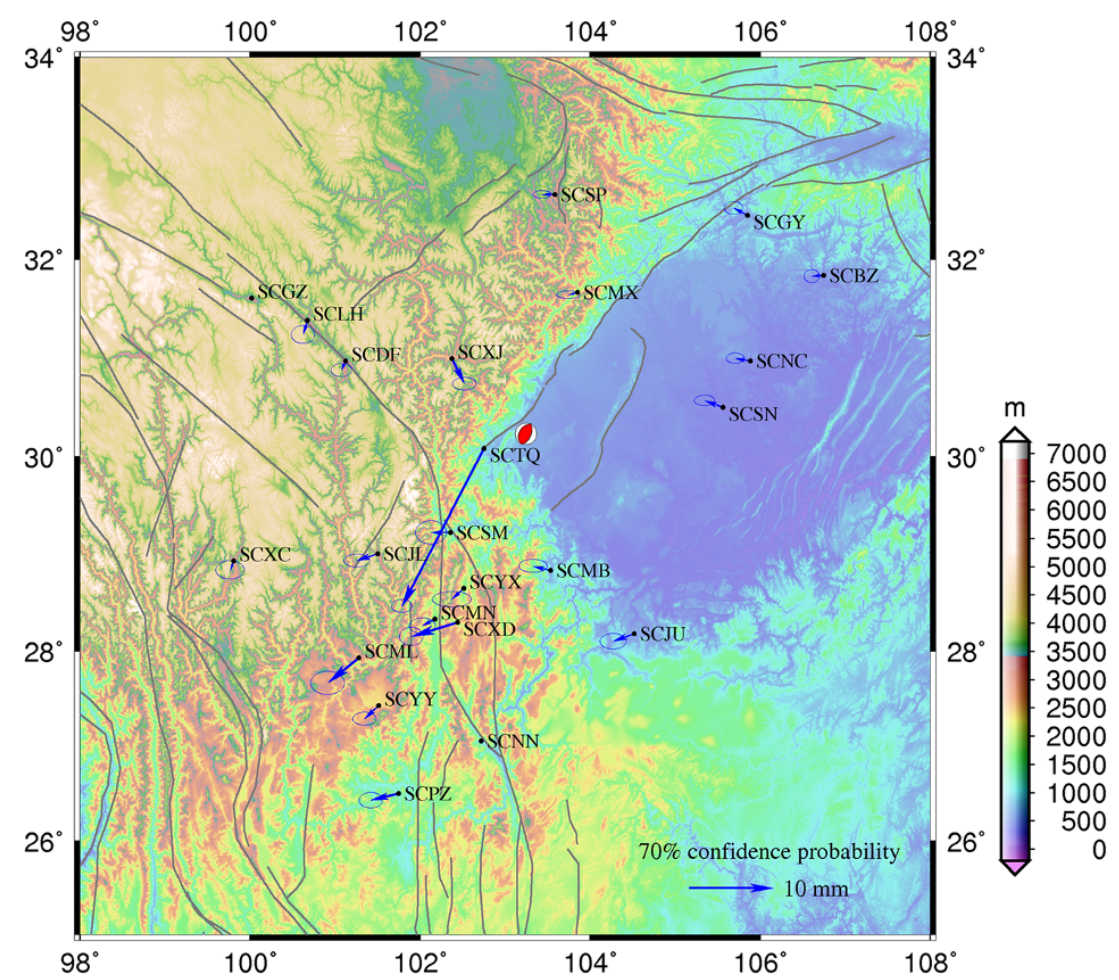

Fig. 2 Horizontal co-seismic static displacements of Lushan earthquake determined by GPS, with $70 \%$ confidence ellipses

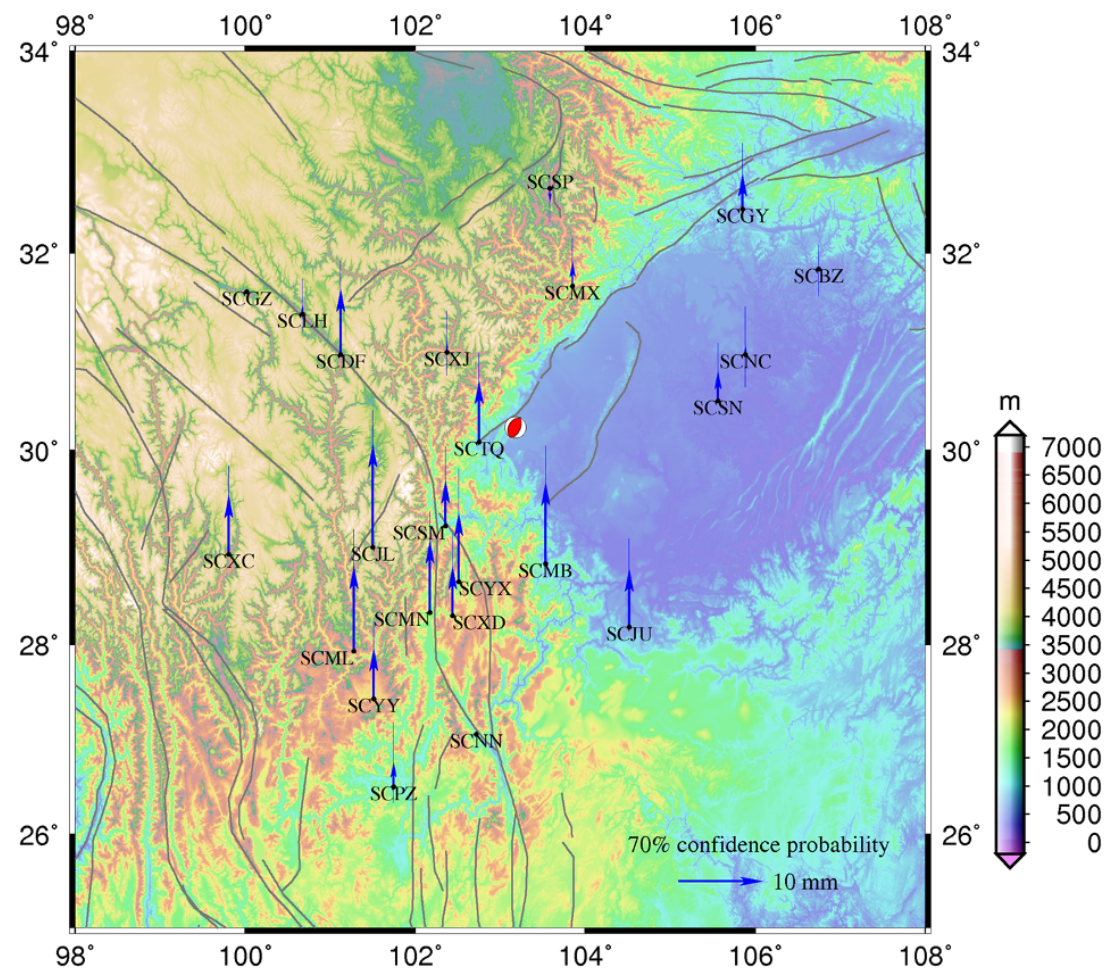

Fig. 3 Vertical co-seismic static displacements of Lushan earthquake determined by GPS, with $70 \%$ confidence ellipses 

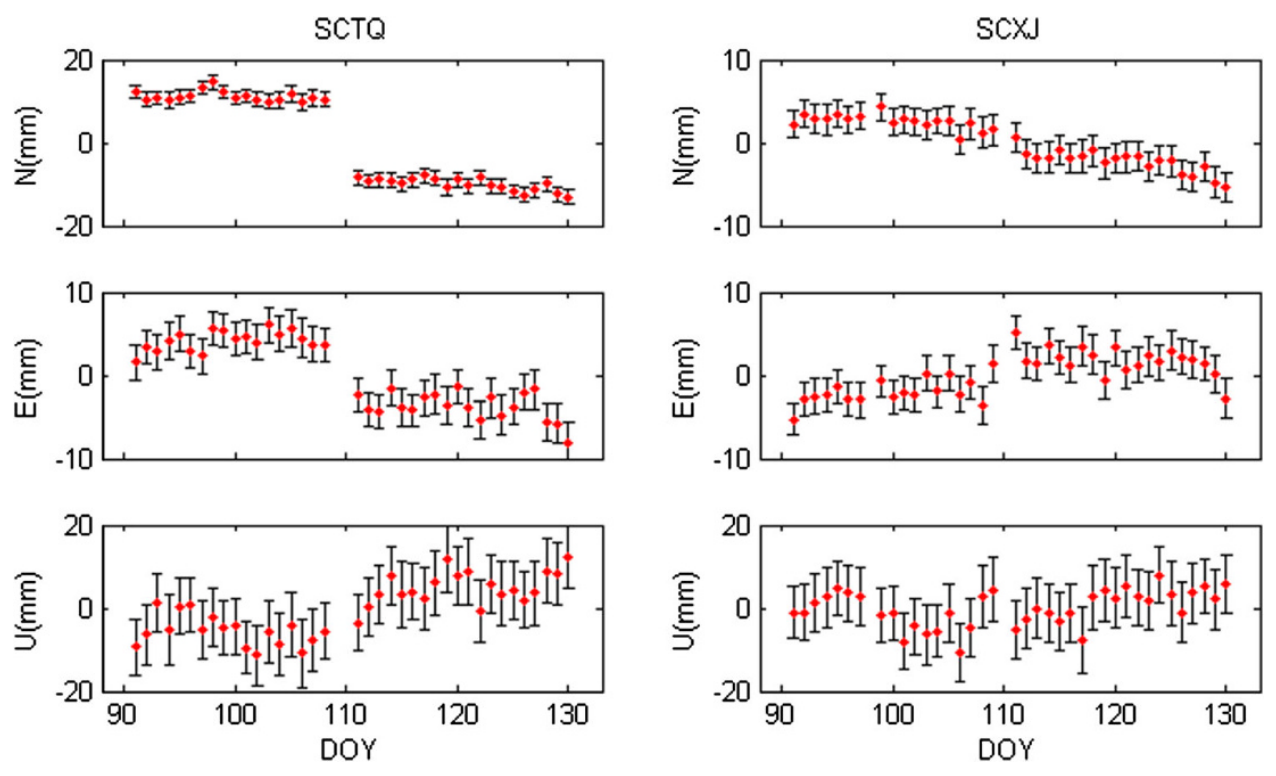

Fig. 4 Position time series of stations SCTQ and SCXJ

\section{Dynamic displacements carried out by kinematic solutions of HRGPS}

We analyze the epoch-by-epoch solutions of the first $10 \mathrm{~min}$ in April 20th performed by high-rate GPS data and obtain 3D time series of surface dynamic displacements. Since the earthquake took place at 00:02:46 UTC, the first 10-min data would record the entire process of the earthquake.

The 3D time series of surface displacements are showed in Fig. 5. The subplots from left to right show the North, East and Up component separately. The time series of stations arranged from bottom to top are at increasing distance from the epicenter. In the time window (0-600 s), the mean of the displacement is subtracted from the origin value for each component of each station. We estimate the possible arrival time of surface waves according to the focal solution of The Global CMT Project, taking the speed of surface wave to be $3 \mathrm{~km} / \mathrm{s}$, and mark with magenta dotted lines in each subplot. Red dotted lines indicate the occurrence time of the earthquake.

The arrival of surface waves at SCTQ, SCXJ, and SCSM can be seen clearly, at least in the horizontal components. The station SCTQ shows a significant kinematic displacement of about 4 and $3 \mathrm{~cm}$ peak-to-peak on the north and east component, respectively. For SCXJ and SCSM, the peak-to-peak values of the deformations are 2-3 cm either on the north or the east components. The peak value of the kinematic motion is much larger than the static permanent displacement on each of these sites. The attenuation of surface wave causes reduction in the amplitude of the waveform with the distance from the epicenter. It is only in the east component that we can easily identify the seismic signal of SCMB, while in north component the signal is close to the level of noise (ca. $3 \mathrm{~mm}$ ). It is difficult to interpret the seismic signal directly from the time series for more distant sites. Because of the worse precision of vertical components of GPS positioning and week signals of vertical displacements, seismic signals are submerged in the noise and difficult to be detected.

It should be noted that, although SCNC and SCSN are far from the epicentral area, it is also easier, compared to other far field stations, to identify the seismic signal. It can be seen from the waveform that there is a discernible change in amplitude and frequency when the seismic wave arrives (marked with the red ellipses in Fig. 5). This may be due to the geographical structure of tectonic block in which they are located. As can be seen from Fig. 2, these two stations are located in central Sichuan Basin. Sichuan Basin is characterized by a simple and stable structure, with neither fracture distribution nor obvious internal velocity gradient zone in it (Zhang et al. 2003). Seismic waves propagating in this region will not be blocked so much, which means that the attenuation is low. For other regions, due to the blocking of fault zones and the impacts of structural changes, seismic wave attenuation is large. It means that for far field stations in these areas, it would be more difficult to detect seismic signals.

We also calculate the instantaneous velocity of each epoch by neighboring differential arithmetic, as shown in Fig. 6. We can find that the velocity of each site fluctuates slightly around zero as noises until the seismic wave arrives. Thus, the seismic signals can be easily detected in SCTQ, SCXJ, and SCSM, especially the $2.5 \mathrm{~cm} / \mathrm{s}$ variation of SCTQ's velocity. The magnitude and the direction of 


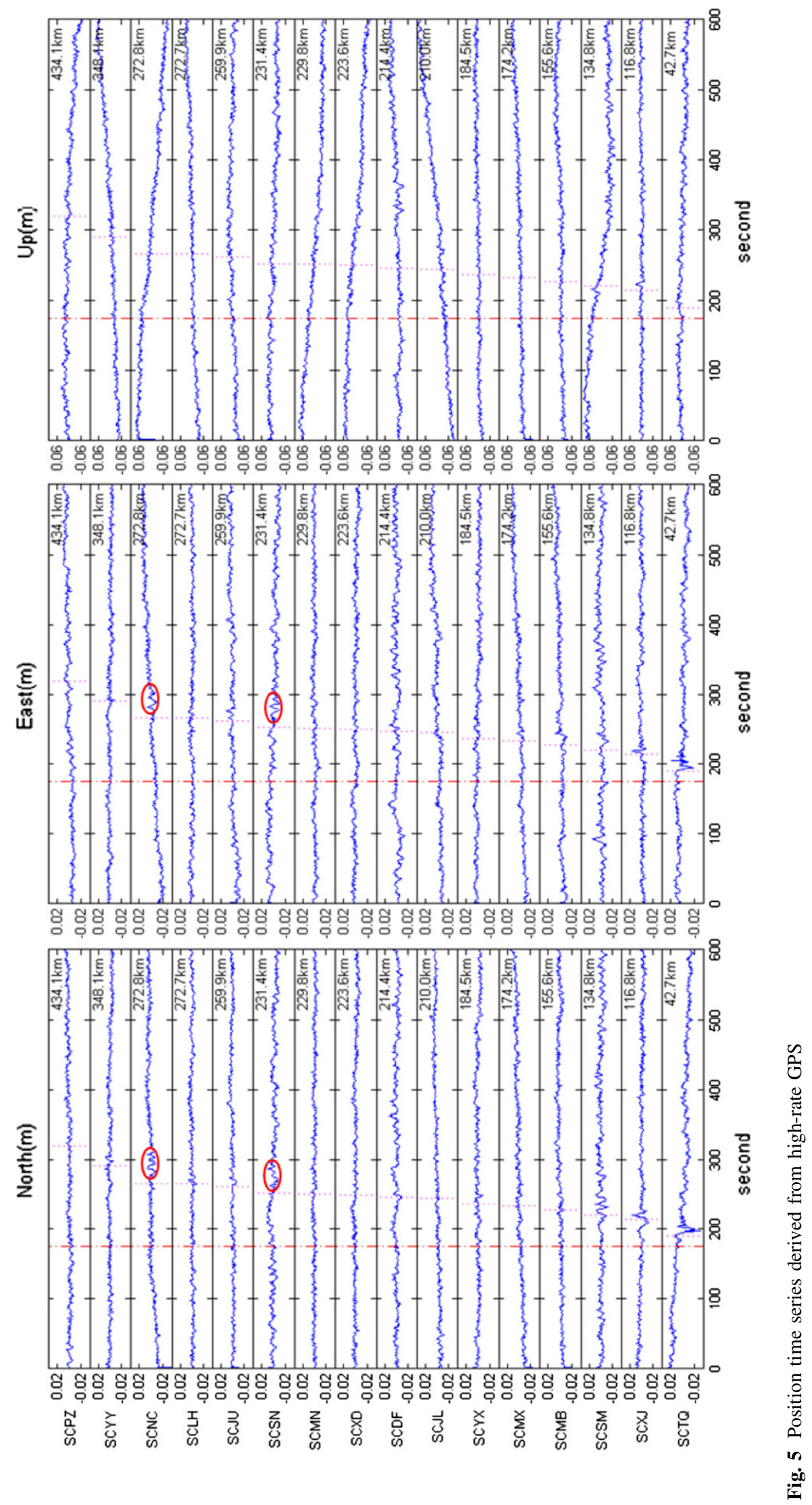



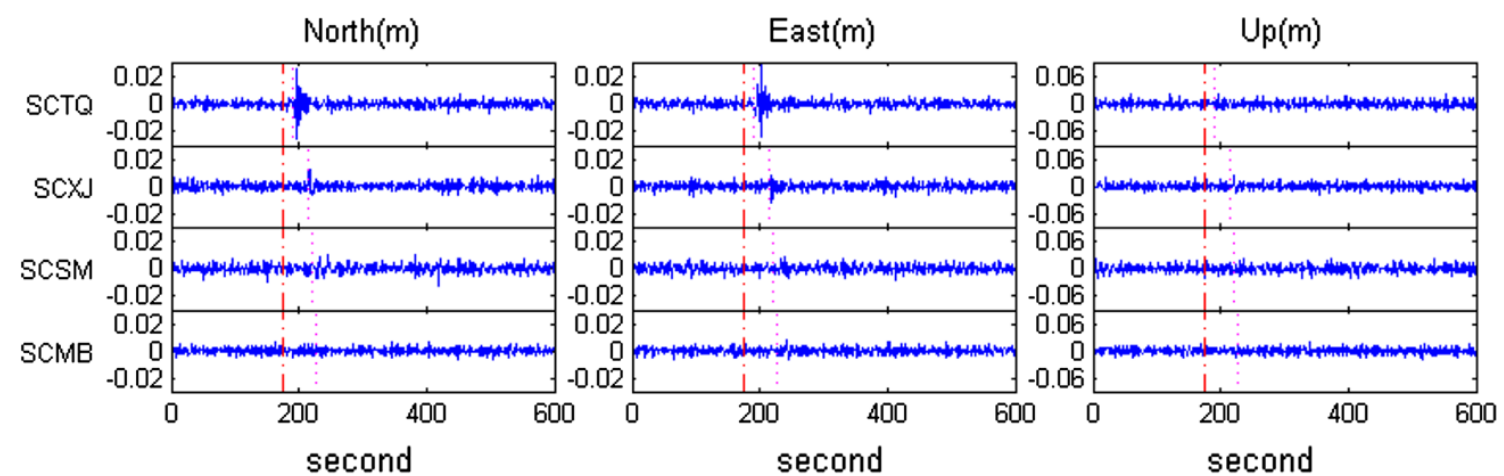

Fig. 6 Velocity time series of some SCTQ, SCXJ, SCSM, and SCMB

each site's velocity vary severely, meaning that the earthquake provides high frequency dynamic response of the stations.

\section{Discussion and conclusions}

Conventional static GPS observations and high-rate GPS observations collected from more than 20 stations in Sichuan are processed to compute the co-seismic displacements and short-term instantaneous surface movements during Lushan earthquake. The characteristics of surface movements and deformations during Lushan earthquake are then analyzed in different time scales. The result shows that:

(1) The static displacements caused by Lushan earthquake are limited to several centimeters. The station SCTQ, which is located $43 \mathrm{~km}$ from the epicenter, has the largest static displacement of about $2 \mathrm{~cm}$, while almost all the other stations have insignificant displacements of less than $5 \mathrm{~mm}$.

(2) The co-seismic displacement field shows that the GPS stations in the east of Sichuan-Yunnan region shift $5-10 \mathrm{~mm}$ to the southwest and rise $5-10 \mathrm{~mm}$, and the stations in the middle-west of Sichuan Basin move $1-2 \mathrm{~mm}$ to the northwest and rise less than $2 \mathrm{~mm}$, respectively.

(3) Large kinematic motions are observed in the near field stations within about $150 \mathrm{~km}$. The station SCTQ has the largest kinematic displacement of about 4 and $3 \mathrm{~cm}$ peak-to-peak on the north and east component, respectively. On each of these sites, the peak-to-peak value of the kinematic motion is much greater than the static permanent displacement. The short-term dynamic information also shows that the seismic waves attenuate fast. The waveform amplitudes reach the noise level (ca. 3 and $10 \mathrm{~mm}$ on the horizontal and vertical components, respectively) at stations located at a distance greater than $150 \mathrm{~km}$ from the epicenter, except SCNC and SCSN.
(4) Two stations in central Sichuan Basin-SCNC and SCSN have significant kinematic motions during the earthquake although they are more than $200 \mathrm{~km}$ away from the epicenter.

The duration of an earthquake is very short (usually only tens of seconds). This kind of instantaneous motion can be captured by high-rate GPS. Although it is widely used in earthquake monitoring, dynamic solution of high-rate GPS has much lower precision than static solution does. For farfield or weak seismic signals, it turns to be inefficient due to strong noises. Conventional static solution with high accuracy up to $\mathrm{mm}$ level can be used for monitoring precisely crustal movements and permanent displacements caused by the earthquake. However, it is of low temporal resolution (usually daily solution). What's more, in order to get satisfactory result, long time of observations or multi-periods of measurements are needed. In this case, integrating the two methods in seismic studies deserves further discussions.

Acknowledgments This study is supported by the National Natural Science Foundation of China (Granted Nos. 41174029 and 41204028), the Polar Strategic Research Foundation of China (Granted No. 20110205), the Open Research Fund of Key Laboratory for Polar Science of State Oceanic Administration (Granted No. KP201201), and the Science and Technology Project of National Administration of Surveying, Mapping, and Geoinformation (Granted name Polar Geomatics Technology Test).

\section{References}

Bock Y, Nikolaidis RM, de Jonge PJ et al (2000) Instantaneous geodetic positioning at medium distances with the global positioning system. J Geophys Res 105(B12):28223-28253

Boehm J, Niell A, Tregoning P et al (2006) Global mapping function (GMF): a new empirical mapping function based on numerical weather model data. Geophys Res Lett 33:L07304

Boehm J, Heinkelmann R, Schuh H (2007) A global model of pressure and temperature for geodetic applications. J Geodesy 81(10):679-683

Choi K, Bilich A, Larson KM et al (2004) Modified sidereal filtering: implications for high-rate GPS positioning. Geophys Res Lett 31(22):L22608 
Dziewonski AM, Chou TA, Woodhouse JH (1981) Determination of earthquake source parameters from waveform data for studies of global and regional seismicity. J Geophys Res: Solid Earth (1978-2012) 86(B4):2825-2852

Ekström G, Nettles M, Dziewoński AM (2012) The global CMT project 2004-2010: centroid-moment tensors for 13,017 earthquakes. Phys Earth Planet Interiors 200:1-9

Estey LH, Meertens CM (1999) TEQC: the multi-purpose toolkit for GPS/GLONASS data. GPS Solut 3(1):42-49

Herring T, King RW, McClusky S (2010a) GAMIT reference manual, release 10.4. Massachussetts Institute of Technology, Cambridge

Herring T, King RW, McClusky S (2010b) GLOBK reference manual, release 10.4. Massachussetts Institute of Technology, Cambridge

Liu J, Yi GX, Zhang ZW et al (2013) Introduction to the Lushan, Sichuan M7.0 earthquake on 20 April 2013. Chin J Geophys 56(4):1404-1407 (in Chinese with English abstract)

Meng GJ, Ren JW, Jin HL et al (2007) Data processing methods of high rate GPS and its application to seismology. Recent Dev World Seismol 7:26-31 (in Chinese)

Ragheb AE, Clarke PJ, Edwards SJ (2007) GPS sidereal filtering: coordinate-and carrier-phase-level strategies. J Geodesy 81(5):325-335

Wang XS, Diao GL, Wang Y et al (2011) Discussion on usage of GPS observational data and focal mechanism in earthquake prediction research: comment on Wang Xiu wen's paper. Chin J Geophys 54(11):2984-2990 (in Chinese with English abstract)

Wang WM, Hao JL, Yao ZX (2013) Preliminary result for rupture process of Apr 20, Lushan Earthquake, Sichuan, China. Chin J Geophys 56(4):1412-1417 (in Chinese with English abstract)
Xu SG, xiong YL, Liao H (2010) Static and kinematic analysis of coseismic deformation of Wenchuan Ms8.0 earthquake. J Geodesy Geodyn 30(3):27-30 (in Chinese with English abstract)

Xu SG, Xiong YL, Huang DF et al (2011) Applied research of long range kinematic GPS data processing in seismic monitoring. Sci Surv Mapp 36(2):88-90 (in Chinese with English abstract)

Yao X, Zhang YS (2009) Co-seismic deformation of "5.12" Wenchuan earthquake based on D-InSAR. J Geomech 15(2):151-161 (in Chinese with English abstract)

Yin HT, Xiao GR, Zhang L (2012) Study on method for selecting reference station in high rate GPS positioning using TRACK during earthquake. J Geodesy Geodyn 32(4):15-19 (in Chinese with English abstract)

Zeng XF, Luo Y, Han LB et al (2013) The Lushan MS7.0 earthquake on 20 April 2013: a high angle thrust event. Chin J Geophys 56(4):1418-1424 (in Chinese with English abstract)

Zhang PZ (2008) Coseismic displacement field of the Ms8.0 Wenchuan earthquake in 2008 Determined by GPS. Sci China Ser D Earth Sci 38(10):1195-1206 (in Chinese with English abstract)

Zhang PZ, Deng QD, Zhang GM et al (2003) Active tectonic blocks and strong earthquakes in the continent of China. Sci China Ser D Earth Sci 46(2):13-24 (in Chinese with English abstract)

Zhang Y, Xu LS, Chen YT (2013) Rupture process of the Lushan 4.20 earthquake and preliminary analysis on the disaster causing mechanism. Chin J Geophys 56(4):1408-1411 (in Chinese with English abstract) 